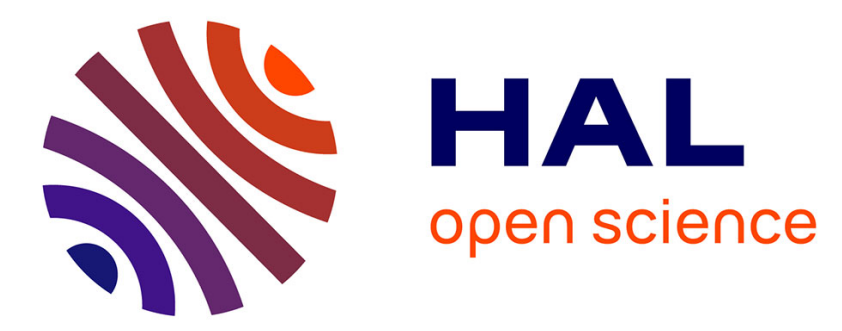

\title{
Directional emission control and increased light extraction in GaN photonic crystal light emitting diodes
}

K. Mcgroddy, A. David, E. Matioli, M. Iza, S. Nakamura, S. Denbaars, J.S. Speck, Claude Weisbuch, E.L. Hu

\section{- To cite this version:}

K. Mcgroddy, A. David, E. Matioli, M. Iza, S. Nakamura, et al.. Directional emission control and increased light extraction in GaN photonic crystal light emitting diodes. Applied Physics Letters, 2008, 93 (10), pp.103502. 10.1063/1.2978068 . hal-00818799

\section{HAL Id: hal-00818799 \\ https://hal-iogs.archives-ouvertes.fr/hal-00818799}

Submitted on 5 Apr 2016

HAL is a multi-disciplinary open access archive for the deposit and dissemination of scientific research documents, whether they are published or not. The documents may come from teaching and research institutions in France or abroad, or from public or private research centers.
L'archive ouverte pluridisciplinaire HAL, est destinée au dépôt et à la diffusion de documents scientifiques de niveau recherche, publiés ou non, émanant des établissements d'enseignement et de recherche français ou étrangers, des laboratoires publics ou privés. 


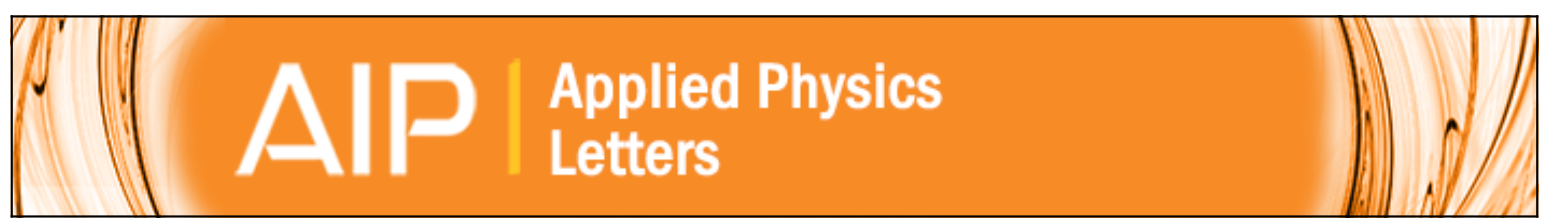

\section{Directional emission control and increased light extraction in GaN photonic crystal light emitting diodes}

K. McGroddy, A. David, E. Matioli, M. Iza, S. Nakamura, S. DenBaars, J. S. Speck, C. Weisbuch, and E. L. $\mathrm{Hu}$

Citation: Applied Physics Letters 93, 103502 (2008); doi: 10.1063/1.2978068

View online: http://dx.doi.org/10.1063/1.2978068

View Table of Contents: http://scitation.aip.org/content/aip/journal/apl/93/10?ver=pdfcov

Published by the AIP Publishing

\section{Articles you may be interested in}

Emission aperture size limited the guided mode extraction characteristics of GaN-based ultrathin-film photonic crystal micro-light-emitting diodes

Appl. Phys. Lett. 101, 023109 (2012); 10.1063/1.4734509

Polarized light extraction in m-plane GaN light-emitting diodes by embedded photonic-crystals Appl. Phys. Lett. 98, 251112 (2011); 10.1063/1.3602319

Highly-directional emission patterns based on near single guided mode extraction from GaN-based ultrathin microcavity light-emitting diodes with photonic crystals

Appl. Phys. Lett. 97, 013108 (2010); 10.1063/1.3459970

Enhanced light extraction in light-emitting diodes with photonic crystal structure selectively grown on $\mathrm{p}-\mathrm{GaN}$ Appl. Phys. Lett. 96, 181110 (2010); 10.1063/1.3427352

Enhanced light extraction from GaN-based green light-emitting diode with photonic crystal Appl. Phys. Lett. 91, 181109 (2007); 10.1063/1.2804005

\section{AIP $\left.\right|_{\text {APL Photonics }}$}

APL Photonics is pleased to announce Benjamin Eggleton as its Editor-in-Chief

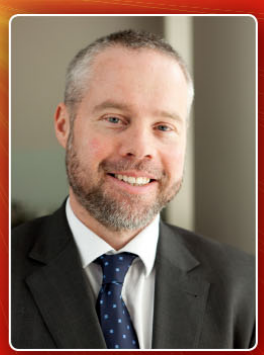




\title{
Directional emission control and increased light extraction in GaN photonic crystal light emitting diodes
}

\author{
K. McGroddy, A. David, ${ }^{\text {a) }}$ E. Matioli, M. Iza, S. Nakamura, S. DenBaars, J. S. Speck, \\ C. Weisbuch, ${ }^{\text {b) }}$ and E. L. Hu \\ Materials Department, University of California, Santa Barbara, California 93106-5050, USA
}

(Received 20 June 2008; accepted 11 August 2008; published online 8 September 2008)

\begin{abstract}
Limitations in extraction efficiency of gallium nitride $(\mathrm{GaN})$ photonic crystal $(\mathrm{PhC})$ light emitting diodes (LEDs) are addressed by implementing an LED design using both two-dimensional PhCs in-plane and index guiding layers (IGLs) in the vertical direction. The effects of PhCs on light extraction and emission directionality from GaN LEDs are studied experimentally. Angular-resolved electroluminescence clearly shows the combined effect of controlling the vertical mode profile with the IGLs and tailoring the emission profile with the periodicity of the $\mathrm{PhC}$ lattice. Increases in directional emission as high as 3.5 times are achieved by taking advantage of this directionality and guided mode control. (C) 2008 American Institute of Physics. [DOI: 10.1063/1.2978068]
\end{abstract}

$\mathrm{GaN}$ has become the prominent material for blue-green light emitting diodes (LEDs) and efficient white light sources. A limiting factor to achieving high efficiencies is that when no light extraction techniques are employed, only a small percentage of the light escapes from the LED $\left(\sim 1 / 4 n^{2}\right.$ per surface) because of total internal reflection (TIR). ${ }^{1}$ Various methods have been employed to increase light extraction such as surface roughening ${ }^{2,3}$ and geometrical modification; $;{ }^{4,5}$ however, these methods rely on random light redirecting events. Early on, photonic crystals ${ }^{6}(\mathrm{PhCs})$ were studied as a means of controllably extracting guided light in other material systems. ${ }^{71}$ The added advantage from $\mathrm{PhC}$ extraction is that, when designed properly, the emission direction can be tailored, increasing light emission in useful directions and reducing the need for lossy reflectors. However, improvements in PhC GaN LEDs have been limited to factors of $\sim 1.5-2$ times $^{12-15}$ despite much higher increases predicted theoretically. ${ }^{16}$ These limitations are due in part to an unoptimized vertical design that does not achieve maximum interaction of the guided modes with the $\mathrm{PhC}$ and the use of nonoptimal lattice constants.

This work demonstrates the ability to take advantage of the specific nature of the interaction of the PhCs with the guided light to both increase light extraction and tailor the emission profile of GaN LEDs. The majority of emitted light in a GaN LED, trapped by TIR, propagates in the form of guided modes, with $22 \%$ trapped in the sapphire substrate and $66 \%$ in the GaN. ${ }^{15} \mathrm{PhCs}$ patterned in the GaN couple the $\mathrm{GaN}$ guided modes into extracted modes by diffraction of the in-plane vector, $k_{\|}=k_{\| 0}-G$, where $k_{\|}$and $k_{\| 0}$ are the modified and original in-plane wave vectors, respectively, and $G$ is the reciprocal lattice vector, which depends on the $\mathrm{PhC}$ lattice constant. When the periodicity is chosen correctly, the modified in-plane wave vector falls within the air escape cone, resulting in extraction to air at an angle dependent on the specific lattice constant within this range. This allows one to tailor the emission profile of the LED with the $\mathrm{PhC}$ lattice

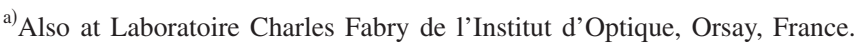
Electronic mail: mcgroddy@engineering.ucsb.edu.

b) Also at Laboratoire de Physique de la Matière Condensée, Ecole Polytechnique, CNRS, 91220, Palaiseau, France.
}

constant as demonstrated by Wierer et al. ${ }^{13}$ and discussed theoretically by David et al.. ${ }^{16}$ Additionally, as shown previously ${ }^{15}$ introducing a lower index guiding layer (IGL) such as $\mathrm{AlGaN}$ forms cap layer modes (CLMs) with increased $\mathrm{PhC}$ and quantum well (QW) overlap and results in extraction of light that was previously trapped. In this work we achieved significantly higher increases in light extraction than previously demonstrated in addition to directional control of emitted light by improved tailoring of both the vertical structure and the PhC lattice.

PhC LED samples were fabricated with indium tin oxide (ITO) $p$-contacts and $\mathrm{Ni} / \mathrm{Au} p$-contacts, referred to as ITO LEDs and Ni/ Au LEDs, respectively. The LED material was grown by metalorganic chemical vapor deposition on double-side polished sapphire substrates. The structures consist of a $200 \mathrm{~nm}$ nucleation layer followed by a $4 \mu \mathrm{m}$ $n$-GaN buffer layer, a $100 \mathrm{~nm} n$-InGaN, a $360-650 \mathrm{~nm}$ $n-\mathrm{Al}_{0.12} \mathrm{Ga}_{0.88} \mathrm{~N} \quad\left(n_{\mathrm{GaN}^{-}} n_{\mathrm{AlGaN}} \sim 0.06\right) \quad$ IGL, $100 \mathrm{~nm} n-\mathrm{GaN}$ contact layer, $\mathrm{InGaN} / \mathrm{GaN}$ multi-QW region, a $20 \mathrm{~nm}$ $\mathrm{Al}_{0.20} \mathrm{Ga}_{0.80} \mathrm{~N}$ electron blocking layer, and a $280 \mathrm{~nm} p-\mathrm{GaN}$ layer. The effects of variations in the IGL will be discussed elsewhere. The peak emission wavelength was $430 \mathrm{~nm}$ for the ITO LEDs and $405 \mathrm{~nm}$ for the Ni/Au LEDs. Triangular lattice PhCs with lattice constants of 185, 200, 215, and $230 \mathrm{~nm}$, depths of $120 \mathrm{~nm}$ (ITO LEDs) or $250 \mathrm{~nm}$ (Ni/Au LEDs), and air fill factors of $30 \%$ were formed by electron beam lithography and reactive ion etching using a $\mathrm{SiO}_{2}$ mask. LEDs with $800 \times 800 \mu \mathrm{m}^{2}$ areas were formed with identical non-PhC LEDs surrounding each PhC LED. $100 \mu \mathrm{m}$ diameter circular $p$-contacts were deposited in the center of each LED in an unetched area. The area of the PhC region is $400 \times 400 \mu \mathrm{m}^{2}$ (ITO LEDs) or $500 \times 500 \mu \mathrm{m}^{2}$ (Ni/Au LEDs) (Fig. 1).

The effects of the PhCs on LED performance were characterized and in all cases direct comparisons are made only to nearby LEDs on the same wafer to eliminate the effects of material variation. For all samples, the electrical characteristics of non-PhC LEDs are identical to PhC LEDs, indicating that the $\mathrm{PhC}$ patterning does not have any detrimental effects on electrical performance. The AlGaN IGL also does not impact electrical performance as long as the $n$-contact is made on the $n$-GaN layer above it, not on the AlGaN. 


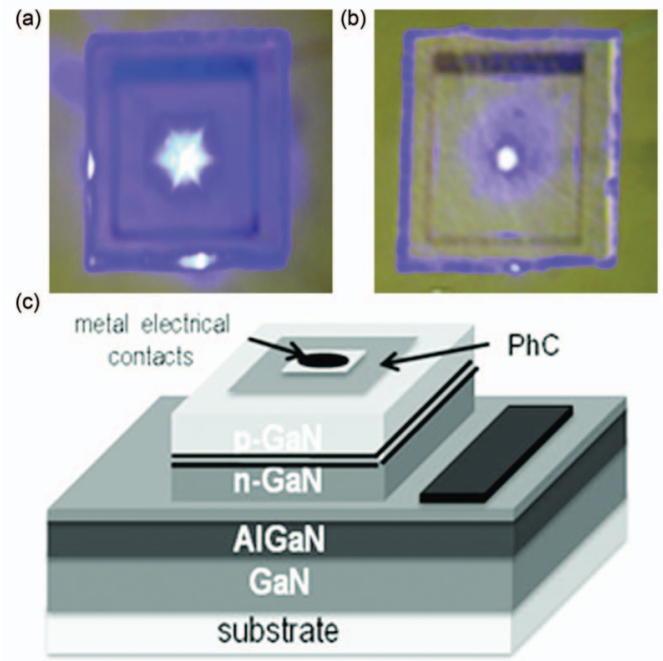

FIG. 1. (Color) Optical image of a (a) $200 \mathrm{~nm}$ PhC LED (inset) PhC reciprocal lattice (b) non-PhC LED showing the increased diffraction from the $\mathrm{PhC}$ especially along the $\Gamma M$ directions of the triangular lattice. (c) $\mathrm{PhC}$ LED design.

Angular resolved electroluminescence (EL) data is used to deduce the band structure of the $\mathrm{PhC}$ above the air light line and reveals the specific details of the interaction of the guided modes with the $\mathrm{PhC}$ as previously described. ${ }^{11}$ Figure 2 shows the angular EL and corresponding band structures for ITO LEDs with varying PhC lattice constants, measured in the $\Gamma M$ direction of the PhCs. The background emission, weakly modulated by Fabry-Perot interferences can be seen as well as sharp emission lines arising from $\mathrm{PhC}$ diffraction. Each line corresponds to a guided mode that has been diffracted above the light line by the $\mathrm{PhC}$. The more intense line corresponds to the CLM. From the GaN and AlGaN dispersion lines plotted on the band structure in Fig. 2(e), it can be seen that the CLM has an effective index, $n_{\mathrm{GaN}}>n_{\mathrm{CLM}}$ $>\mathrm{nAlGa}_{\mathrm{N}}$, corresponding to a low order mode. The strong

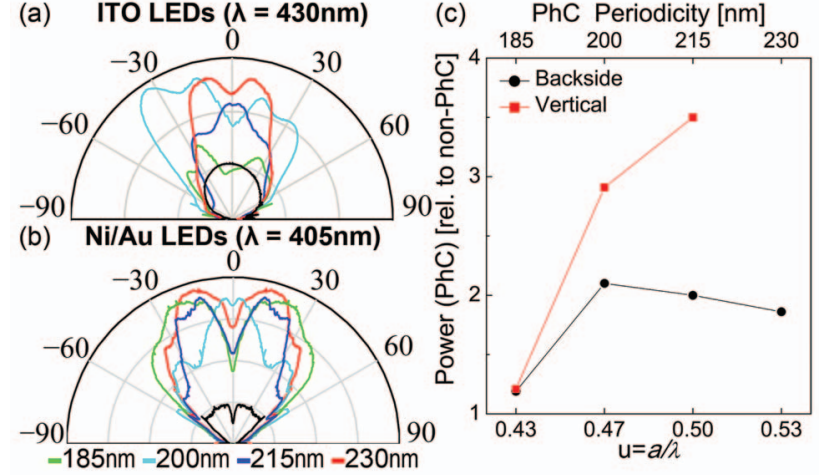

FIG. 3. (Color) [(a)-(b)] Emission profile for PhC LEDs with varying PhC lattice constants (color) compared to a non-PhC LED (black) in the $\Gamma M$ direction, measured by angular EL. (c) (ITO LEDs) Increase in PhC LED output power relative to non PhC LED output power plotted as a function of reduced frequency $u=a / \lambda$. (red) Increase in vertical output power $(\mathrm{NA}=0.4)$ and (black) increase in output power measured from the backside $(\mathrm{NA}=0.87)$.

intensity is an indication of both strong emission into the mode and strong extraction of the mode due to large spatial overlap with the QW and $\mathrm{PhC}$, respectively. The high order modes are not noticeably affected by the IGL but the wellextracted CLM now receives much of the emission that previously went to poorly extracted low-order modes.

The emission profile varies markedly with changes in lattice constant, as seen in the angular spectra (Fig. 2) and the angular dependent emission [Figs 3(a) and 3(b)]. The most vertical emission profile is observed near the secondorder diffraction condition $a / \lambda=0.50$, corresponding to lattice periods of $215 \mathrm{~nm}$ for the $430 \mathrm{~nm}$ ITO LEDs and $200 \mathrm{~nm}$ for the $405 \mathrm{~nm} \mathrm{Ni} / \mathrm{Au}$ LEDs. Furthermore, when the $\mathrm{PhC}$ is designed to diffract light vertically, very large enhancements in vertical output power are observed. The vertical emission is measured on ITO LEDs by placing a photodetector with a numerical aperture of 0.4 over the LED and

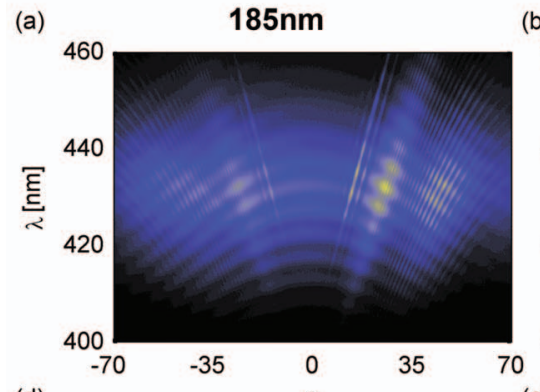

(d)

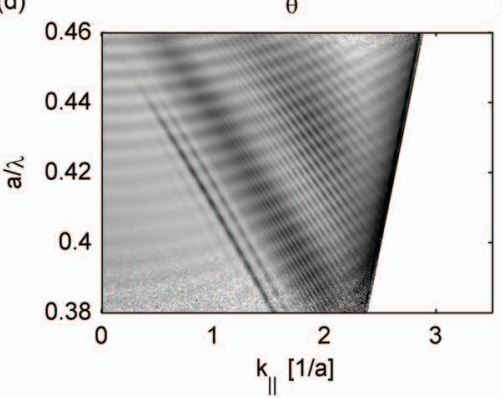

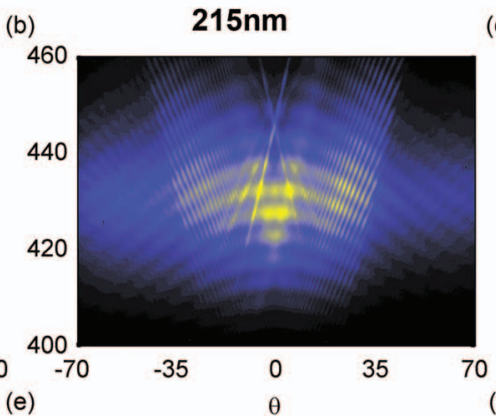

(e)
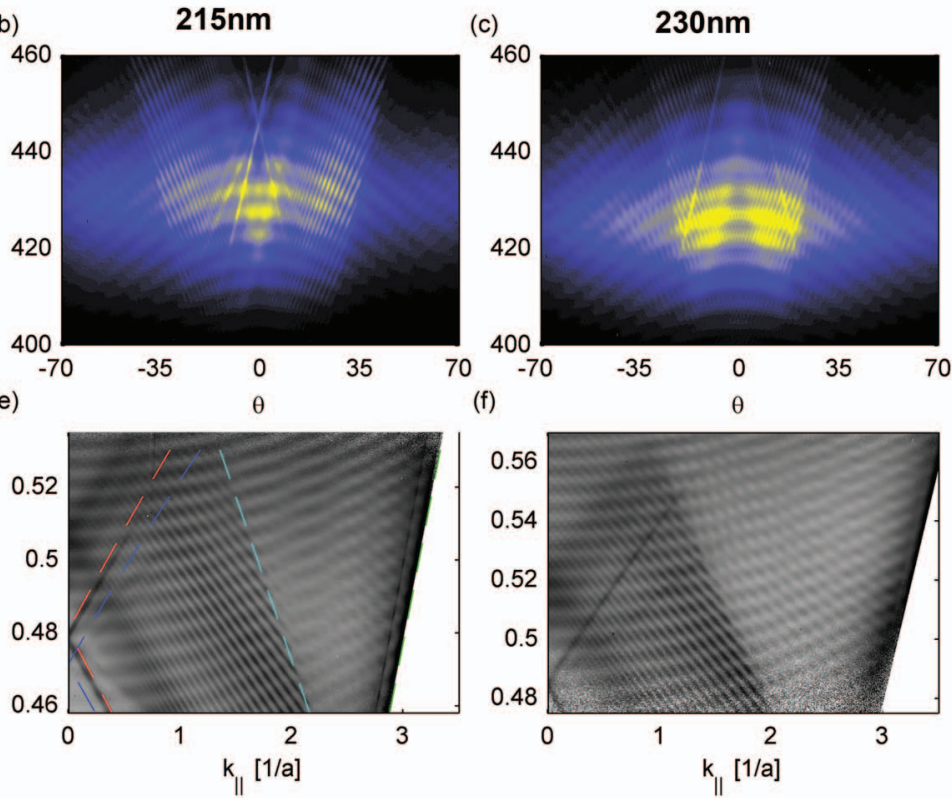

(f) $\theta$

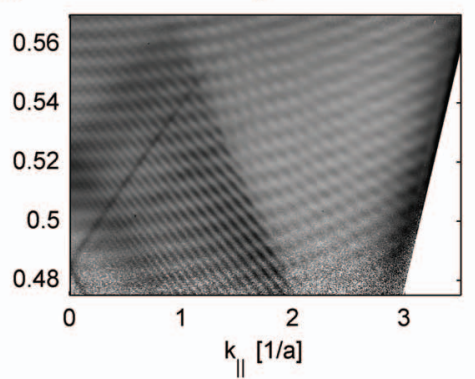


the increase in vertical emission from PhC LEDs is plotted in Fig. 3(c). To make a fair comparison, the ITO LEDs are measured so that the direct vertical emission is not blocked by the contact. A maximum increase in vertical output power of 3.5 times is achieved for a lattice period of $215 \mathrm{~nm}$ on the ITO LEDs $(\lambda=430 \mathrm{~nm})$. This large increase is obtained by controlling both the vertical mode profile and the lattice constant to extract the modes, especially the strong CLM, vertically. This increase in directional emission exemplifies the specific advantage of $\mathrm{PhCs}$ when optimal lattice constants are employed. It should also be noted that the lengths of the $\mathrm{PhCs}$ used in this case are 100 or $150 \mu \mathrm{m}$ compared to only $50-80 \mu \mathrm{m}$ in previous experiments, ${ }^{2-15}$ resulting in more complete extraction of all of the modes since the extraction length for the modes is expected to be between 60-200 $\mu \mathrm{m} .{ }^{15}$ Therefore, strong enhancements in directional emission can be achieved by designing the PhC lattice constant based on the emission wavelength of the LED.

Emission was measured from the back of the wafer using a photodetector with a numerical aperture of 0.87 to include a larger collection angle. The enhancement in backside output power for ITO LEDs, averaged from $10-20 \mathrm{~mA}$, is plotted as a function of reduced frequency in Fig. 3(c). At $127 \mathrm{~A} / \mathrm{cm}^{2}$, the average increase is 1.9 times and the maximum is 2.3 times with a $200 \mathrm{~nm} \mathrm{PhC}$. The increase in integrated intensity from the angular EL in the $\Gamma M$ direction of the PhC for ITO LEDs shows an average enhancement of 1.8 times and a maximum of 2.3 times with a $200 \mathrm{~nm} \mathrm{PhC} \mathrm{at}$ $64 \mathrm{~A} / \mathrm{cm}^{2}$, comparable to the enhancement measured from the backside. Ni/Au LEDs show an average enhancement in integrated angular intensity of 3.1 times and maximum of 3.5 times with a $185 \mathrm{~nm} \mathrm{PhC}$. If this trend is compared to what is expected theoretically, ${ }^{16}$ we find very good agreement. The maximum enhancement occurs at $a / \lambda=\sim 0.46$, lower than for vertical emission. Once the lattice constant is large enough to extract all modes to air, further increases lead to increased diffraction to the substrate and larger extraction lengths. However, this decrease is minimal over a broad range of $a / \lambda$ and can be eliminated with the use of epoxy ${ }^{16}$ so that the emission direction can be tailored while still achieving near maximum enhancements in total output power. Larger enhancements for the Ni/Au LEDs could result from several factors such as larger PhC pattern area, increased hole depth, and the nontransparent $p$-contact.

Preliminary $4 \pi$ integrated measurements, made using an integrated sphere on $\mathrm{Ni} / \mathrm{Au}$ LEDs, show an increase in total output power of 2.1 times and 1.8 times for the 200 and $230 \mathrm{~nm}$ lattice constant PhC LEDs, respectively. The increase in output power measured by this method is lower because all emission, including emission from the edge of the LED chip, is included, thus minimizing PhC LED's advantage of increasing vertical emission. If we assume equal internal quantum efficiencies in PhC LEDs and non-PhC LEDs and an external quantum efficiency of $24 \%$ for the non-PhC LED (4\% per surface), the extraction efficiencies of the 200 and $230 \mathrm{~nm}$ PhC LEDs are 50\% and 43\%, respectively. While this is still lower than theoretically expected (in principle at best $24 \%+66 \%$ ), further enhancements can be expected with improvements to the vertical structure by increasing the index contrast of the IGL and optimizing the QW placement.

In conclusion, we have demonstrated enhancements in light extraction and directionality of PhC LEDs by modifying the vertical structure and tailoring the $\mathrm{PhC}$ lattice constant. Directional emission has been increased 3.5 times and total extraction efficiency has more than doubled. Further optimization of the vertical structure will lead to even greater increases in efficiency from PhC LEDs in the future. The ability to both significantly increase light extraction and control emission direction with optimized PhC LEDs has enormous benefits for efficient LED operation.

The authors would like to thank Hisashi Masui for his assistance in packaging and integrated measurements. The NSF Fellowship provided funding for K.M. and research funding was provided by DOE SSL under Project No. DEFC26-06NT42857.

${ }^{1}$ H. Benisty, H. De Neve, and C. Weisbuch, IEEE J. Quantum Electron. 34, 1612 (1998).

${ }^{2} 2$ T. Fujii, Y. Gao, R. Sharma, E. L. Hu, S. P. DenBaars, and S. Nakamura, Appl. Phys. Lett. 84, 855 (2004).

${ }^{3}$ C. Huh, K. S. Lee, E. J. Kang, and S. J. Park, J. Appl. Phys. 93, 9383 (2003).

${ }^{4}$ J. J. Wierer, D. A. Steigerwald, M. R. Krames, J. J. O'Shea, M. J. Ludowise, G. Christenson, Y. C. Shen, C. Lowery, P. S. Martin, S. Subramanya, W. Gotz, N. F. Gardner, R. S. Kern, and S. A. Stockman, Appl. Phys. Lett. 78, 3379 (2001).

${ }^{5}$ M. R. Krames, M. Ochiai-Holcomb, G. E. Hofler, C. Carter-Coman, E. I. Chen, I. H. Tan, P. Grillot, N. F. Gardner, H. C. Chui, J. W. Huang, S. A. Stockman, F. A. Kish, M. G. Craford, T. S. Tan, C. P. Kocot, M. Hueschen, J. Posselt, B. Loh, G. Sasser, and D. Collins, Appl. Phys. Lett. 75, 2365 (1999).

${ }^{6}$ E. Yablonovitch, J. Opt. Soc. Am. B 10, 283 (1993).

${ }^{7}$ A. A. Erchak, D. J. Ripin, S. Fan, P. Rakich, J. D. Joannopoulos, E. P. Ippen, G. S. Petrich, and L. A. Kolodziejski, Appl. Phys. Lett. 78, 563 (2001).

${ }^{8}$ M. Rattier, H. Benisty, R. P. Stanley, J. F. Carlin, R. Houdre, U. Oesterle, C. J. M. Smith, C. Weisbuch, and T. F. Krauss, IEEE J. Sel. Top. Quantum Electron. 8, 238 (2002).

${ }^{9}$ T. Baba, K. Inoshita, H. Tanaka, J. Yonekura, M. Ariga, A. Matsutani, T. Miyamoto, F. Koyama, and K. Iga, J. Lightwave Technol. 17, 2113 (1999).

${ }^{10}$ M. Boroditsky, T. F. Krauss, R. Coccioli, R. Vrijen, R. Bhat, and E. Yablonovitch, Appl. Phys. Lett. 75, 1036 (1999).

${ }^{11}$ A. David, C. Meier, R. Sharma, F. S. Diana, S. P. DenBaars, E. Hu, S. Nakamura, C. Weisbuch, and H. Benisty, Appl. Phys. Lett. 87, 101107 (2005)

${ }^{12}$ T. N. Oder, K. H. Kim, J. Y. Lin, and H. X. Jiang, Appl. Phys. Lett. 84, 466 (2004).

${ }^{13}$ J. J. Wierer, M. R. Krames, J. E. Epler, N. F. Gardner, M. G. Craford, J. R. Wendt, J. A. Simmons, and M. M. Sigalas, Appl. Phys. Lett. 84, 3885 (2004).

${ }^{14}$ D. H. Kim, C. O. Cho, Y. G. Roh, H. Jeon, Y. S. Park, J. Cho, J. S. Im, C. Sone, Y. Park, W. J. Choi, and Q. H. Park, Appl. Phys. Lett. 87, 203508 (2005).

${ }^{15}$ A. David, T. Fujii, R. Sharma, K. McGroddy, S. Nakamura, S. P. DenBaars, E. L. Hu, C. Weisbuch, and H. Benisty, Appl. Phys. Lett. 88, 061124 (2006).

${ }^{16}$ A. David, H. Benisty, and C. Weisbuch, J. Disp. Technol. 3, 133 (2007). 